УДК 517.9

\title{
The Calculation of Magnetoresistance Coefficient for Multilayer Magnetic Structures
}

\author{
Dmitriy E. Romanovskiy* \\ Vladimir V. Prudnikov ${ }^{\dagger}$ \\ Pavel V. Prudnikov $\ddagger$ \\ Omsk State University \\ Mira, 55a, Omsk, 644077, Russia
}

Received 05.12.2016, received in revised form 10.06.2017, accepted 20.01.2018

\begin{abstract}
We performed a simulations of magnetic properties for the multilayer structures $\mathrm{Fe} / \mathrm{Cr} / \mathrm{Fe}$ and $\mathrm{Co} / \mathrm{Cu} / \mathrm{Co}$ using the Monte Carlo methods and the anisotropic Heisenberg model. The calculation of magnetoresistance coefficient is implemented in case of CPP geometry for the different thicknesses of the ferromagnetic films. The calculated dependence of the magnetoresistance coefficient on temperature is agreed very well to the experimental data. The values of the thickness of the ferromagnetic film corresponding to the highest value of magnetoresistance coefficient were determined.
\end{abstract}

Keywords: effect of giant magnetoresistance, magnetic multilayered structures, ultrathin films, magnetoresistance coefficient, anisotropic Heisenberg model, Monte Carlo methods.

DOI: 10.17516/1997-1397-2018-11-6-733-737.

\section{Introduction}

The giant magnetoresistance (GMR) effect has been observed in the multilayer structures which are composed of alternating magnetic layers ( $\mathrm{Fe}, \mathrm{Co}, \mathrm{Ni}$ ) separated by nonmagnetic metal layers $(\mathrm{Cr}, \mathrm{Cu})$ with the thickness of the nm order. The thickness of the nonmagnetic layer are selected in such way that interaction between the magnetic layers should be antiferromagnetic. Adjacent ferromagnetic layers are oriented opposite to each other due to this interaction between the magnetic moments.

Placing this structure in an external magnetic field leads to a significant change in electrical resistance. The values of the magnetoresistance coefficient, reaching more than $100 \%$ at low temperatures, are responsible for the high perspectivity of such nanostructures for a new generation of magnetic recording heads for hard disks, ultra-sensitive magnetic sensor, the active elements of the spintronic magnetoresistive memory etc. [1].

\section{Monte Carlo methods of calculating the magnetoresistance coefficient}

The magnetic properties of ultrathin films based on $\mathrm{Fe}$, $\mathrm{Co}$ and $\mathrm{Ni}$ on non-magnetic metal substrates can be described with the use of the anisotropic Heisenberg model [2]. The Hamilto-

\footnotetext{
*romfizz898@gmail.com

†prudnikv@univer.omsk.su

${ }^{\ddagger}$ prudnikp@univer.omsk.su

(c) Siberian Federal University. All rights reserved
} 
nian of model in case when the magnetization vector is oriented perpendicular to the film plane $(\mathrm{Fe} / \mathrm{Cr})$ is given as

$$
H=-J \sum_{i, j}\left\{\left[1-\Delta_{1}(N)\right]\left(S_{i}^{x} S_{j}^{x}+S_{i}^{y} S_{j}^{y}\right)+S_{i}^{z} S_{j}^{z}\right\}
$$

and for the in plane magnetisation $(\mathrm{Co} / \mathrm{Cu})$ the The Hamiltonian is

$$
H=-J \sum_{i, j}\left\{\left(S_{i}^{x} S_{j}^{x}+S_{i}^{y} S_{j}^{y}\right)+\left[1-\Delta_{2}(N)\right]\left(S_{i}^{z} S_{j}^{z}\right)\right\} .
$$

Here $S_{i}=\left(S_{i}^{x}, S_{i}^{y}, S_{i}^{z}\right)$ is the three-dimensional unit vector in the $i$ lattice node, $J$ is the exchange integral characterizing the exchange interaction of nearest spins, $\Delta_{1,2}$ is the anisotropy parameters. The values of $\Delta_{1,2}=0$ in (1) and (2) corresponds to the isotropic Heisenberg model, $\Delta_{1}=1$ in (1) corresponds to the Ising model and $\Delta_{2}=1$ in (2) to XY model.

Parameters $\Delta_{1,2}(N)$ take into account the effective influence of the anisotropy generated by the crystal field of the substrate with the magnetic properties of the film depending on the thickness of the $N$ in terms of monolayers. Fig. 1 shows the dependence of $\Delta_{1}(N)$ for the system $\mathrm{Fe} / \mathrm{Cr}(100)$ and $\Delta_{2}(N)$ for the system $\mathrm{Co} / \mathrm{Cu}(100)$. The values of $\Delta_{1}(N)$ and $\Delta_{2}(N)$ were calculated proportional to the dependence of the critical temperature for $\mathrm{Fe}$ and $\mathrm{Co}$ films on their thickness.
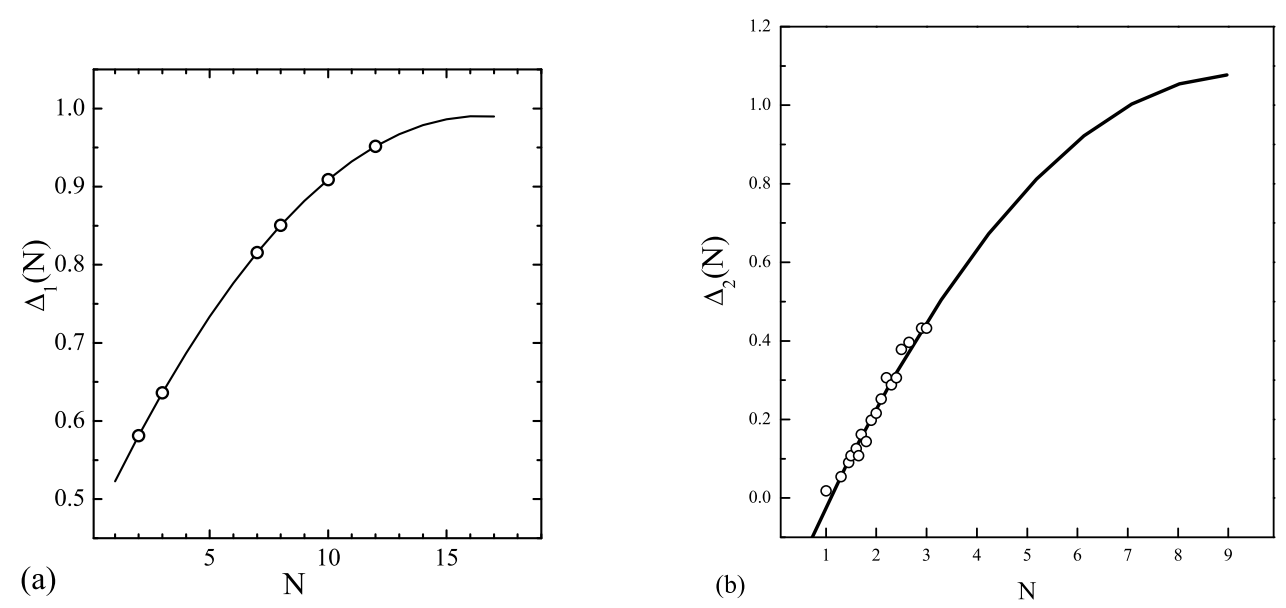

Fig. 1. The dependence of the anisotropy parameter of ferromagnetic film $\triangle_{1,2}$ on the thickness $N$ for the systems $\mathrm{Fe} / \mathrm{Cr}(100)$ (a) and $\mathrm{Co} / \mathrm{Cu}(100)$ (b). The circles correspond to the experimental values of the critical temperature, used in calculations

We represent the following elements of the developed technique [3] for the determination of the magnetoresistance coefficient of multilayer magnetic structures in case of CPP-geometry (current perpendicular to the plane) using the Monte Carlo methods.

Let us denote the value of the resistance for the groups of electrons with spin up (down) during the passage of the FM layer and on the border with the NM layer $R_{\text {uparrow }}\left(R_{\text {downarrow }}\right)$. If $H>H_{s}$, where $H_{s}$ is a saturation field, the magnetization of the adjacent ferromagnetic layers are oriented parallel to each other (ferromagnetic configuration). The total resistance of this structure is given as $R_{H}=2 R_{\uparrow} R_{\downarrow} /\left(R_{\uparrow}+R_{\downarrow}\right)$. In case of absence of an external magnetic field, the magnetization of the two magnetic layers are oriented antiparallel (antiferromagnetic 
configuration). The total resistance is equal to $R_{0}=\left(R_{\text {uparrow }}+R_{\text {downarrow }}\right) / 2$. Thus, the magnetoresistance coefficient can be calculated by the formula:

$$
\delta_{h}=\frac{R_{H}-R_{0}}{R_{0}}=\frac{\left(R_{\uparrow}-R_{\downarrow}\right)^{2}}{4 R_{\uparrow} R_{\downarrow}}=\frac{\left(\mathbf{J}_{\uparrow}-\mathbf{J}_{\downarrow}\right)^{2}}{4 \mathbf{J}_{\uparrow} \mathbf{J}_{\downarrow}},
$$

where $\mathbf{J}_{\uparrow, \downarrow}=e n_{\uparrow, \downarrow}\left\langle\mathbf{V}_{\uparrow, \downarrow}\right\rangle$ is the current density. Hear, $n_{\uparrow, \downarrow}$ is the density of electrons with spin projections on the $z$ axis equal to $+1 / 2$ and $-1 / 2, n=n_{\uparrow}+n_{\downarrow}$ is the total electron density, $\left\langle\mathbf{V}_{\uparrow, \downarrow}\right\rangle$ is the averaged velocity of electrons with corresponding spin projections. The electron densities with spin up and down can be expressed through the magnetization of film $n_{\uparrow, \downarrow} / n=(1 \pm m) / 2$, which is determined in the process of Monte Carlo simulation of its magnetic properties. The averaged electron velocity $\left\langle\mathbf{V}_{\uparrow, \downarrow}\right\rangle$ can be expressed through an electron mobility and the intensity of external electric field $\mathbf{E}$, and after that through a probability of electron jump in unit time from $i$-cell to the next cell in the direction of electric field [3] with averaging over all film cells:

$$
\left\langle\mathbf{V}_{\uparrow, \downarrow}\right\rangle=\mu_{\uparrow, \downarrow} \mathbf{E}=\frac{e}{T} \mathbf{E}\left\langle\exp \left(-\frac{\Delta E_{i, \uparrow, \downarrow}}{T}\right)\right\rangle,
$$

where $\mu$ is the electron mobility, $\Delta E_{i}$ characterizes the change of system energy connected with electron jump from $i$-cell to a next cell. $E_{i, \uparrow, \downarrow}$ is defined by the relation:

$$
E_{i, \uparrow, \downarrow}=\mp J_{1}\left[\sum_{j \neq i} S_{j}^{z}\left(n_{j, \uparrow}-n_{j, \downarrow}\right)+S_{i}^{z}\left(n_{i, \uparrow}-n_{i, \downarrow}\right)\right],
$$

where the summation is realized over the cells closest to the $i$ cell.

On the basis of the above relations, we performed the calculation of the magnetoresistance coefficient on the temperature for the magnetic structures $\mathrm{Fe} / \mathrm{Cr}(100) / \mathrm{Fe}$ and $\mathrm{Co} / \mathrm{Cu}(100) / \mathrm{Co}$ with the different thicknesses $N$ of ferromagnetic layers.

\section{Calculation results}

Figs. 2a and 3a show the results of Monte Carlo calculation of the temperature dependence of magnetoresistance coefficient for the trilayer magnetic structures $\mathrm{Fe} / \mathrm{Cr}(100) / \mathrm{Fe}$ and $\mathrm{Co} / \mathrm{Cu}(100) / \mathrm{Co}$ on different thicknesses $N$ of ferromagnetic films with the values of the exchange integral $J=2 \cdot 10^{-14} \mathrm{erg}$ for Fe and $J=4.4 \cdot 10^{-14} \mathrm{erg}$ for Co. The resulting dependence of the magnetoresistance coefficient on the $N$ for the structure $\mathrm{Fe} / \mathrm{Cr} / \mathrm{Fe}$ corresponds to the identified in [2] dimensional changes in the critical temperature of ferromagnetic phase transition for the $\mathrm{Fe} / \mathrm{Cr}$ system. Fig. $2 \mathrm{~b}$ and $3 \mathrm{~b}$ show that the calculated temperature dependence of the magnetoresistance coefficient is in good agreement with the experimental data measured for structures $\mathrm{Fe} / \mathrm{Cr}$ and $\mathrm{Co} / \mathrm{Cu}$ in case of $\mathrm{CPP}$-geometry [4].

The developed method allows to predict the value of the thickness of the ferromagnetic film, corresponding to the maximum value of the magnetoresistance coefficient for trilayer structures, $N=15$ for the $\mathrm{Fe} / \mathrm{Cr} / \mathrm{Fe}$ and $N=9$ for $\mathrm{Co} / \mathrm{Cu} / \mathrm{Co}$.

Investigations were supported by Russian Science Foundation through project no. 14-12-00562, by Russian Foundation of Basic Research through grants no. 17-02-00279, 18-42-550003 and by the grant no. MD-6868.2018.2 of Council on grants of the President of the Russian Federation. The calculations were performed using the resources provided by the Shared Facility Center "Data Center of FEB RAS" (Khabarovsk), the Supercomputing Center of Lomonosov Moscow State University, Moscow Joint Supercomputer Center and St. Petersburg Supercomputer Center of the Russian Academy of Sciences. 

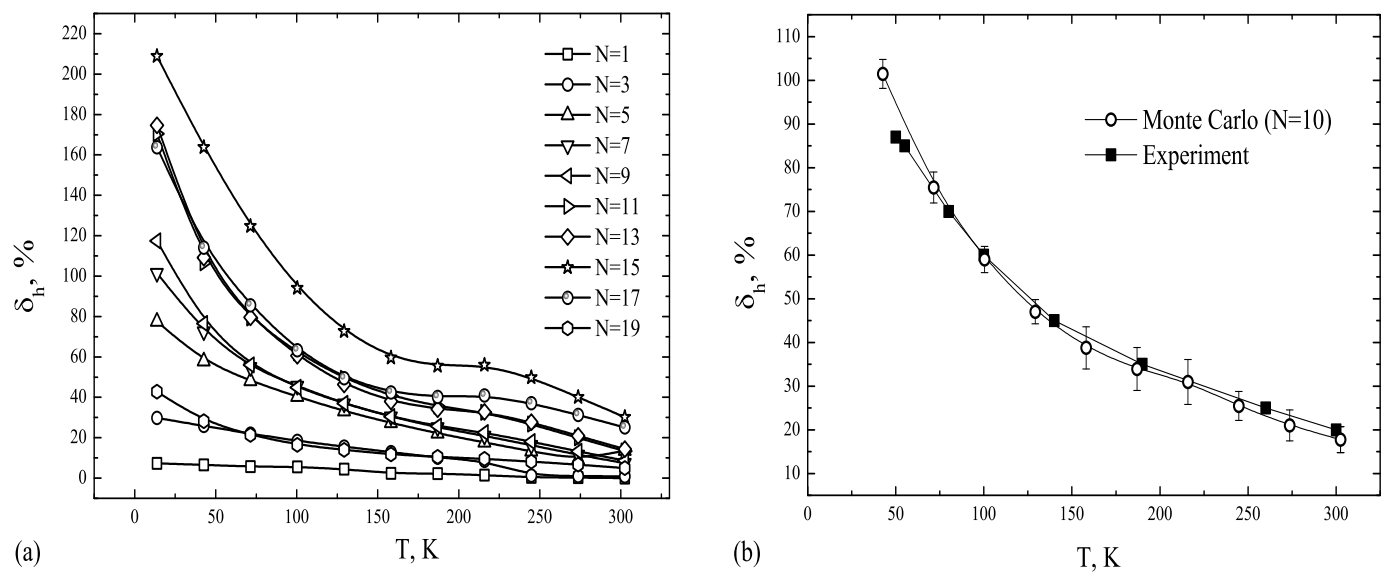

Fig. 2. The dependence of the magnetoresistance of a trilayer structure $\mathrm{Fe} / \mathrm{CR}(100)$ on the temperature for different values of the thickness of Co films (a), comparison of the calculated and experimentally measured in [4] temperature dependence of the magnetoresistance with the thickness of the Co films $3.0 \mathrm{~nm}(N=10)(\mathrm{b})$
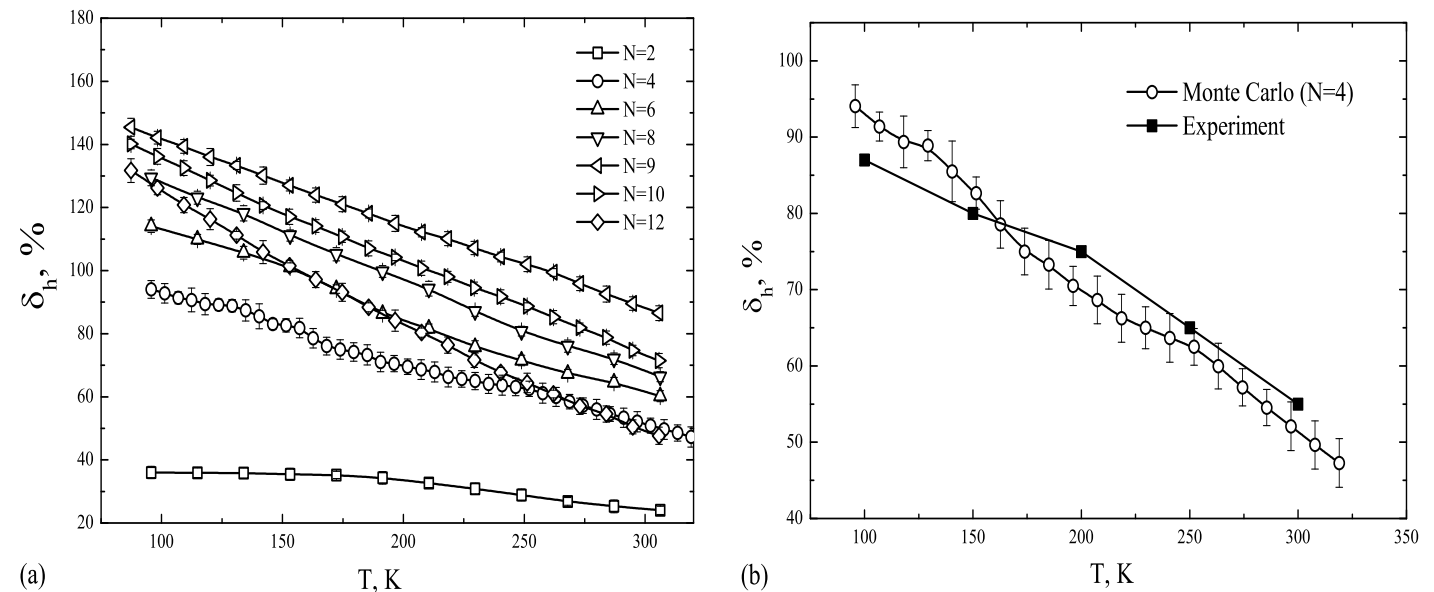

Fig. 3. The dependence of the magnetoresistance of a trilayer structure $\mathrm{Co} / \mathrm{Cu}(100)$ on the temperature for different values of the thickness of Co films (a), comparison of the calculated and experimentally measured in [4] temperature dependence of the magnetoresistance with the thickness of the Co films $1.2 \mathrm{~nm}(N=4)(\mathrm{b})$

\section{References}

[1] C.Chappert, A.Fert, F.N. Van Dau, Nat. Mater., 6(2007), 813-823.

[2] P.V.Prudnikov, V.V.Prudnikov, M.A.Medvedeva, JETP Lett., 100(2014), 446-450.

[3] V.V.Prudnikov, P.V.Prudnikov, D.E.Romanovskiy, JETP Lett., 102(2015), 668-673.

[4] J.Bass, W.P.Pratt, J. Magn. Magn. Mater., 200(1999), 274-289. 


\section{Расчет коэффициента магнитосопротивления мультислойных магнитных структур}

Дмитрий Е. Романовский

Владимир В. Прудников

Павел В. Прудников

Омский государственный университет

Мира, 55а, Омск, 644077

Россия

Осуществлено моделирование магнитных свойств мультислойных структур $\mathrm{Fe} / \mathrm{Cr} / \mathrm{Fe} u$ $\mathrm{Co} / \mathrm{Cu} /$ Со методами Монте-Карло с использованием анизотропной модели Гейзенберга. Осуществлен расчет коэффициента магнитосопротивления для ТПП-геометрии для разных значений толщин ферромагнитных пленок. Показано, что рассчитанная температурная зависимость коэффициента магнитосопротивления находится в хорошем соответствии с экспериментальными данными. Определены значения толщин ферромагнитных пленок, соответствующие наибольшему значению коэффициента магнитосопротивления в данных структурах.

Ключевые слова: гигантское магнитосопротивление, мультислойные магнитные структуры, ультратонкие магнитные пленки, коэффициент магнитосопротивления, анизотропная модель Гейзенберга, методы Монте-Карло. 